\title{
TERRITÓRIO, DITADURA E DESENVOLVIMENTO: PERSPECTIVAS HISTÓRICAS SOBRE OS PROGRAMAS DE REGIONALIZAÇÃO NO BRASIL
}

\author{
Danielle Heberle Viegas* \\ * Unilasalle, Canoas, Rio Grande do Sul, RS, Brasil
}

\begin{abstract}
Resumo
O artigo pretende agregar contribuições para os estudos sobre regionalização no Brasil com a apresentação de um panorama da institucionalização do programa nacional de desenvolvimento regional, no quadro delimitado pela ditadura civil-militar (1964-85). Para isso, são pormenorizados órgãos $e$ instituições especializadas, publicações de experts, entre outras fontes documentais primárias inéditas. Como principal inferência, assume-se que o projeto nacional-desenvolvimentista, associado ao autoritarismo, encontrou nos projetos de regionalização o seu território de materialização por excelência. Esse traço pode ser observado na caracterização de regiões baseada unicamente em critérios econômicos, nos privilégios legislativos concedidos à instalação de fábricas fora das grandes capitais, em planos e projetos de remoção de bairros residenciais em prol de indústrias e, finalmente, na associação da ideia do conceito de regionalização ao de desenvolvimento.

Palavras-chave

Regionalização; Ditadura civil-militar; Urbanização; Planejamento urbano; Desenvolvimentismo.
\end{abstract}




\title{
TERRITORY, DICTATORSHIP AND DEVELOPMENT: HISTORICAL PERSPECTIVES REFLECTING REGIONALIZATION PROGRAMS IN BRAZIL
}

\author{
Danielle Heberle Viegas* \\ * Unilasalle, Canoas, Rio Grande do Sul, RS, Brasil
}

\begin{abstract}
The article aims at adding contributions to the studies of regionalization in Brazil, presenting an overview concerning the institutionalization of the national program of regional development, within the framework defined by the Civil-Military Dictatorship (1964-85). In order to achieve this purpose, institutions, publications of experts, among other unpublished primary sources will be detailed. We assume that the national-developmentalist project, closely attached to authoritarianism, encountered in the projects of regionalization its reason for being. Such a trait may be observed in the characterization of regions solely under economic criteria targeting industrialization, in the political, scientific and corporate conflicts which approached the urban topic and, finally, in the association regarding the concept of regionalization as an intrinsic function of development.

Keywords

Regionalization; Civil-military dictatorship; Urbanization; Urban planning; Developmentalism.
\end{abstract}




\section{TERRITÓRIO, DITADURA E DESENVOLVIMENTO: PERSPECTIVAS HISTÓRICAS SOBRE OS PROGRAMAS DE REGIONALIZAÇÃO NO BRASIL}

Danielle Heberle Viegas

1. Introdução

A ascensão da questão urbana enquanto problema público no Brasil está relacionada ao quadro temporal delimitado entre a República Velha e a ditadura militar. No período em tela, ocorreram modificações na administração institucional e no aparato jurídico, além do fortalecimento do tópico na agenda da grande imprensa e da especialização de profissionais. Nessa conjuntura, as cidades brasileiras foram concebidas como provedoras da modernidade nacional, visto que "o modelo desejado de desenvolvimento associava produção industrial e condições urbanas de reprodução social, conduzido por um Estado fortemente atuante, verticalizado e hierarquizado" (FERNANDES, 2012, p. 51).

Em uma verdadeira "cadeia de disseminação" (FELDMAN, 2005, p. 277) de ideias, práticas e modelos, o planejamento passou a ser reconhecido como instrumento capaz de conduzir o desenvolvimento territorial brasileiro, tanto em sua dimensão urbana quanto agrária. Parte da historiografia especializada (DÉAK, 1999; VILLAÇA, 1998; FELDMAN, 2009) reconhece como o ápice do planejamento urbano no Brasil o conjunto de medidas implementadas em momentos imediatamente ligados ao golpe militar de 1964. Vale destacar que a noção de planejamento assumiu significados múltiplos no período, enquanto mera declaração de inten-

1. Adota-se aqui o entendimento de "questão urbana” nos termos colocados por Schmidt, ou seja, "um conjunto complexo de demandas políticas e sociais e de caráter urbano” (1986, p. 12). SCHMIDT, B. A questão urbana. Rio de Janeiro: Jorge Zahar,1986. 
ções e estratégias enunciativas, programas de desenvolvimento ou, ainda, planos de desenvolvimento (CAMPOS, 1974, p. 74). Nesse sentido, o presente texto aborda a institucionalização das práticas de regionalização no Brasil, ${ }^{2}$ buscando agregar reflexões sobre como essa acepção se coadunou com o projeto de planejamento desenvolvimentista, um dos marcos da cultura nacional-estatista do país (REIS, 2014).

Metodologicamente, o estudo caracteriza-se por realizar análise qualitativa e de conteúdo fundamentada nos seguintes eixos cotejados ao longo do artigo: a) órgãos, instituições e autarquias; b) publicações de circulação técnico-científicas relacionadas ao tema; c) práticas e medidas executivas, tais como programas, que visavam legitimar o desenvolvimento regional. O recorte temporal está restrito aos anos compreendidos entre 1964 e 1985 e as fontes são oriundas de acervos de pesquisa diversos, notavelmente a biblioteca do Instituto Brasileiro de Geografia e Estatística/IBGE e a biblioteca do Instituto de Pesquisa Econômica Aplicada/IPEA (Rio de Janeiro), Arquivo Nacional (Brasília) e Ibero-Amerikanisches Institut (Berlim, Alemanha).

Para as análises realizadas, compreende-se o território não como um fator preeestabelecido, nem como um reflexo de práticas, e sim por meio de uma dinâmica na qual "a organização política e a organização territorial da nação não podem ser consideradas como dados separados, mas devem ser pensadas unitariamente, como uma organização político-territorial” (SANTOS, 1987, p. 190).

$\mathrm{O}$ trabalho busca somar-se àqueles que analisam o planejamento urbano a partir da circularidade de ideias e práticas (FELDMAN, 2009; SOUZA, 2012; LEME, 1999; MARICATO, 2000) e que vêm suprindo a lacuna existente quanto ao aprofundamento da história das práticas de regionalização no Brasil.

2. "Um arquipélago dissociado": o desenvolvimento regional como alternativa à problemática urbana no Brasil

A exemplo da base diversificada sobre a qual o planejamento urbano se assentou no Brasil, o voluptuoso processo de urbanização do país ${ }^{3}$ não foi alvo de um único eixo de elaboração teórico, tampouco de práticas profissionais oriundas de um grupo exclusivo. As duas vertentes (STEINBERGER, 1976, pp. 63-64) que mais

\footnotetext{
2. Os termos "região", "regionalização” e "desenvolvimento regional” serão aqui analisados com base em sua ocorrência em fontes de pesquisa primárias, e não na historiografia. Para uma revisão conceitual, ver: LENCIONI, S. Região e geografia. São Paulo: Edusp, 2003.

3. José de Souza Martins (1992), por exemplo, assinala como marco para a urbanização o último quarto do século XIX. Quanto ao âmbito latino-americano, ver Fridman e Abreu (2010). Cf. MARTINS, J. de S. Subúrbio. São Caetano do Sul: Editora Hucitec, 1992; FRIDMAN, F.; ABREU, M. A. (Orgs.). Cidades latino-americanas: um debate sobre a formação de núcleos urbanos. Rio de Janeiro: Casa da Palavra, 2010.
} 
encontraram respaldo em publicações científico-acadêmicas foram o planejamento urbano local integrado e a regionalização, perspectiva que será detalhada neste texto.

O binômio regionalização-desenvolvimento possui respaldo histórico, com diferentes mobilizações que podem ser nucleadas em torno de motivos como a colonização de vazios demográficos, a ocupação de áreas para fins de proteção militar e, finalmente, aquela que mais encontrou aderência durante a ditadura civil-militar (embora não só nesse período): a regionalização com fins de equiparação e integração territorial, por meio da industrialização. A especificidade está no fato de que a disciplinarização do território esteve profundamente implicada com a pauta desenvolvimentista, voltada a um modelo de industrialização conduzido por projetos de planejamento estatatais compreendidos como meios de superação do subdesenvolvimento brasileiro (BIELCHOWSKY, 1988, p. 7).

Nesse sentido, a regionalização encontrou aderência tanto no meio técnico-científico e em discussões de âmbito acadêmico como no organograma institucional público que estava sendo montado, fato que marcou as variações e usos dos sentidos do termo, ora como "regionalização", ora como "desenvolvimento regional". ${ }^{4}$ Conforme explicou Almeida: "O governo federal após o golpe militar de 1964 estava preocupado com a espacialização do desenvolvimento econômico e via com grande interesse pesquisas que pudessem organizar o território brasileiro ou dar subsídios para este processo” (2000, p. 168).

Sem embargo, foi divulgado que o "desenvolvimento regional integrado emprestava ordenamento nacional ao progresso brasileiro, dando-se dimensão continental a uma economia que se marcava pela transformação do país num arquipélago dissociado" (MINTER, 1967, p. 3). O território nacional passou a ser encarado como um grande campo de práticas, tendo em vista que "os espaços aparecem cada vez mais como se diferenciando por sua carga de capital” (SANTOS, 2013, p. 143). Desta forma, o programa nacional de desenvolvimento regional foi alvo de ações executivas e envolveu a colonização de áreas consideradas inóspitas, a criação de novos estados na Federação e o reconhecimento institucional de regiões como entidades político-jurídicas. Não bastava, portanto, rascunhar um novo território por meio de mapas; era necessário assegurar o acesso a elas. Para Schmidt (1983, p. 9):

4. É notório que o acréscimo do termo “desenvolvimento", compondo a expressão “desenvolvimento regional”, marca grande parte da documentação produzida pelo poder público em relação ao tema. 
[...] como outros países que experimentaram uma tardia integração no mercado capitalista mundial, o Estado no Brasil tem historicamente tentado ocupar plenamente o território nacional através de colonização dirigida ou subsidiada, através da construção de novos sítios urbanos, e pelo redirecionamento dos fluxos nacionais de urbanização originados nos padrões históricos de comércio.

Programas de desenvolvimento regional e de atenuação de desequilíbrios foram incluídos em publicações estatais (BRASIL, 1974), como é o caso do Programa de ação econômica do governo revolucionário (1964-1966) (BRASIL, 1967). Ainda em 1964, foi originado o Ministério Extraordinário para Coordenação dos Organismos Regionais, ${ }^{5}$ com a prerrogativa da existência das superintendências regionais desde a década de 1950. Surgiram ações como o Programa de Integração Nacional (PIN), que englobava projetos como o Proterra, o Prodoeste e o Provale (BRASIL, 1974), assim como o Sistema de Informações para Planejamento e Avaliação do Desenvolvimento Regional (Sipade).

Em consonância com a arquitetura institucional erigida, emergiu o programa nacional de regionalização no âmbito técnico, acadêmico e cientifico. De acordo com essa perspectiva, os núcleos urbanos eram funcionalizados em igualdade com outras regiões do país, como áreas rurais, florestais, industriais, etc. A teoria encontrou respaldo em instituições de pesquisa, como o Conselho Nacional de Geografia (CNG) e o Instituto Brasileiro de Geografia e Estatística (IBGE), para o qual a pauta regionalização foi central desde as origens, durante o Estado Novo (ALMEIDA, 2000). O próprio IBGE reconheceu e institucionalizou os conceitos teóricos de polarização e homogeneidade por meio de publicações como Subsídios à regionalização (1968) e a Divisão do Brasil em microrregiões homogêneas (1970).

A teoria da regionalização foi divulgada desde o final dos anos 1950 por profissionais como o geógrafo francês Michel Rochefort, cuja atuação no Brasil foi notável, primeiro no IBGE e, posteriormente, junto à Comissão Nacional de Regiões Metropolitanas e Política Urbana (CNPU) e ao Serviço Federal de Habitação e Urbanismo (Serfhau). A principal interlocutora de Rochefort no Brasil foi a geógrafa Lysia Bernardes, que ocupou cargos de grande expressividade no IBGE durante as décadas de 1950 e 1960 (LAMEGO, 2014, p. 5).

Rochefort tornou-se o responsável pela difusão da chamada metodologia das redes urbanas, com ênfase na análise do setor terciário. Em sua obra O problema da regionalização do Brasil, ele propõe uma divisão do território nacional em regiões vazias; regiões de equilíbrio tradicional com fraca densidade demográfica; regiões

5. Lei n. 4.344, de 21 de junho de 1964. 
de equilíbrio tradicional com densidade demográfica forte ou média, além de regiões de crescimento (ROCHEFORT, 1967). A organização do território se daria pela fixação de regiões homogêneas, definidas a partir de classificações tipológicas baseadas em questionários e cartogramas. Essa teorização está associada à chamada geografia aplicada, cuja ascensão esteve ligada ao "contexto nacional-desenvolvimentista, de intervenção estatal na economia e confiança no planejamento" (BOMFIM, 2015, p. 366).

A teoria da regionalização está imbricada com aquela que previa polos de desenvolvimento, elaborado pelo economista, também de origem francesa, François Perroux. Ao passo que a regionalização era ordenada para classificar o país em zonas setoriais, os polos de desenvolvimento serviriam para induzir potencialidades constatadas nos projetos. ${ }^{6}$ Nesses termos, cada área foi funcionalizada de acordo com suas potencialidades econômicas. Esse critério marcou a superação do viés fisiográfico de classificação do território, elaborado por Fábio de Macedo Soares Guimarães, que realizou estudos pioneiros na área em idos da década de 1940 (ALMEIDA, 2000, p. 167).

Essa acepção foi incorporada em publicações oriundas do campo político, caso do Programa Estratégico de Desenvolvimento, datado de 1967, no qual se lê que "a identificação de polos de desenvolvimento de cada região é importante para evitar dispersão de aplicações em conformidade com a orientação do programa estratégico" (MINSTÉRIO DO PLANEJAMENTO E COORDENAÇÃO GERAL, 1967a). O documento aponta a falta de integração como um obstáculo ao desenvolvimento nacional, daí "a necessidade de concepção do planejamento integrado, que deverá abranger quatro aspectos básicos: o econômico, o social, o físico territorial e o institucional" (idem, p. 144).

As atribuições do programa de regionalização ficaram sob o domínio do Ministério do Interior (Minter), o qual, ao lado do Ministério do Planejamento (Miniplan), e suas renomeações sequenciais, formou o alto escalão voltado ao planejamento urbano durante a ditadura militar, tendo em vista que abrigou as principais autarquias e órgãos dedicados ao tema.

O Minter nasce como resultado da divisão daquele que é um dos ministérios mais antigos da história do país, a saber: o Ministério da Justiça e dos Negócios Interiores, cuja origem remonta ao início do período republicano.7 Assim apare-

6. Para mais detalhes sobre os polos de desenvolvimento, consultar: TOLOSA, H. Planejamento regional. Rio de Janeiro: Ipea, 1970, e BRASIL. Pesquisa sobre polos de desenvolvimento e regiões homogêneas no Brasil. Rio de Janeiro: Miniplan - Epea; Biblioteca Ipea, [s.d.].

7. Lei n. 23, de 30 de outubro de 1891, por sua vez relacionada com a Lei de 3 de julho de 1822, que criou a Secretaria de Estado dos Negócios da Justiça. 
ceram enquanto esferas independentes o Ministério da Justiça e o Ministério do Interior; é sobre este último que se intenciona lançar luz. Esse ministério absorveu competências, adicionalmente, do Ministério Extraordinário para Coordenação dos Organismos Regionais, cujos primórdios são vinculados ao golpe de $1964{ }^{8}{ }^{8}$

Foram incluídos entre as competências do Minter: I - o desenvolvimento regional (grifo meu); II - a radicação de populações, a ocupação do território e as migrações internas; III - os territórios federais; IV - o saneamento básico; V - o beneficiamento de áreas e obras de proteção contra secas e inundações e a irrigação; VI - assistência às populações atingidas pelas calamidades públicas; VII - assistência ao índio; VIII - assistência aos municípios; IX - programa nacional de habitação (MINTER, 1967, p. 4). Não por acaso, entre os órgãos e autarquias que o Minter comandou, em temporadas parciais ou integrais, estavam as Superintendências de Desenvolvimento Regional (Sudene, Sudeco, Sudesul, Sudam, Suframa), o Serfhau, o Banco Nacional de Habitação (BNH), o Banco da Amazônia (Basa), o Banco do Nordeste do Brasil (BNB), o Departamento Nacional de Obras contra as Secas (DNOCS) e o Departamento Nacional de Obras e Saneamento (DNOS).

Postos esses dados, chama-se a atenção para o fato de a questão urbana estar inserida em um campo com maior abrangência daquele que historicamente a reivindicou, qual seja, a arquitetura e o urbanismo. O tópico foi incluído, afinal, no Plano Decenal de Desenvolvimento Econômico e Social, publicado em 1967, e detalhado na seção "Desenvolvimento Regional e Urbano", que versava sobre as diretrizes para a formulação de uma política de desenvolvimento regional e a regionalização dos programas industriais (MINISTÉRIO DO PLANEJAMENTO E COORDENAÇÃO GERAL, 1967b).

Assim, a problemática urbana só começou a ser avaliada em nível ministerial quando o Minter perdeu as atribuições relativas à categoria território, com a criação do Ministério do Desenvolvimento Urbano e Meio Ambiente, já na década de 1980..$^{9}$ Apesar das solicitações que remontam aos tempos dos congressos promovidos pelo Instituto Brasileiro de Associação Municipal (Ibam), não foi arregimentado um Ministério do Urbanismo e/ou do Desenvolvimento Urbano. O Estado ditatorial desprezou as sugestões feitas pela Organização dos Estados Americanos (OEA) e sua proposta de criação de um Departamento Nacional de Urbanismo para o Brasil, elaborada em 1941 (FARIA, 2015).

8. Lei n. 4344, de 21 de junho de 1964.

9. Decreto n. 91.145 de 15 de março de 1985. Esse novo ministério teve duas alterações de nome: Ministério da Habitação, Urbanismo e Meio Ambiente (MHU, pelo Decreto n. 95.075, de 22 de outubro de 1987) e Ministério da Habitação e Bem-Estar Social (MBES, pelo Decreto n. 96.634, de 2 de setembro de 1988). 
O mais próximo disso foi, de fato, o Minter, voltado ao gerenciamento territorial como um todo, incluindo fronteiras (territórios federais como Amapá, Rondônia, Roraima) e populações (destaque para migrantes e indígenas), e, enfim, ao urbanismo (cortejado, com notoriedade, em razão do aspecto habitacional). Ecos desse debate são deduzíveis por meio da leitura de ofícios do referido ministério. Em documento que aborda a criação do Sistema de Desenvolvimento Local em meados da década de 1970, o superintende clamava às autoridades para que fosse designada uma "Secretaria Especial de Desenvolvimento Urbano" com vistas a fornecer paridade hierárquica aos setores urbano e ambiental por parte do governo “em face dos investimentos e atuação já previstos no PND”. ${ }^{10}$

A constatação de que a questão urbana fazia parte de uma estrutura político- administrativa ampla é uma brecha interessante para referenciar-se o outro ministério considerado fundamental no quadro institucional que se busca reconstruir. Trata-se do Ministério do Planejamento.

O Miniplan possuía, a priori, a função de coordenação econômica e comandava, naquela época, o Banco Nacional do Desenvolvimento Econômico (BNDE). Mas, no início da década de 1970, o planejamento assumiu um caráter global, não essencialmente relacionado à esfera financeira, como era o caso do Conselho Consultivo de Planejamento (Consplan). Sob a guarda do Miniplan foram incluídos a Financiadora de Estudos e Projetos S/A (Finep), o IBGE e o Instituto de Planejamento Econômico e Social (Ipea).

Eram competências do Miniplan: I - o Plano Geral do governo, sua coordenação e a integração dos planos regionais; II - estudos e pesquisas socioeconômicos, inclusive setoriais e regionais (grifo meu); III - programação orçamentária; proposta orçamentária anual; IV - coordenação da assistência técnica internacional; V - sistemas estatístico e cartográfico nacionais; VI - organização administrativa. Conforme é possível aferir, esse ministério detinha sob sua égide atividades que perspassavam o campo urbanístico.

Ao Miniplan foram agregadas outras instituições, complexificando o organograma do ministério. Em 1972, surge o Sistema Federal de Planejamento (SFP) e, dois anos mais tarde, o ministério se tornaria uma secretaria diretamente ligada a Presidência da República - a Seplan, confirmando a importância do setor junto ao governo e seu caráter executivo. Nessa condição, assumiu as seguintes atribuições: I - a coordenação do sistema de planejamento, orçamento e modernização administrativa, no tocante ao acompanhamento da execução dos planos nacionais de desenvolvimento (grifo meu); II - a coordenação das medidas relativas à

10. A sigla PND, no corpo da citação, refere-se ao Plano Nacional de Desenvolvimento. 
política de desenvolvimento econômico e social; III - a coordenação da política de desenvolvimento científico e tecnológico, principalmente em seus aspectos econômico-financeiros, ressalvada a competência deferida à Secretaria Geral do Conselho de Segurança Nacional; IV - na coordenação de assuntos afins ou interdependentes que interessassem a mais de um ministério, a Seplan se tornaria, pelo comando de seus ministros, o centro das decisões econômicas do país. Sob competência dessa secretaria estavam órgãos diretamente relacionados ao gerenciamento e estudo da questão urbana no país, como o Instituto de Planejamento Econômico e Social (IPEA), o IBGE e o Conselho Nacional de Pesquisas (CNPq).

Quanto às autarquias, a primeira a ser mencionada, não por acaso, é a famosa entidade relacionada ao planejamento urbano no Brasil durante a ditadura civil-militar: trata-se do Serfhau. Sua sigla coloca lado a lado o planejamento urbano e a moradia, que era então o foco das preocupações dos especialistas e do Estado. Foram criadas em 1964, por meio da Lei n. 4.380, juntamente com o Banco Nacional da Habitação (BNH), as Sociedades de Crédito Imobiliário e as Letras Imobiliárias. No artigo $1^{\circ}$ da referida Lei se indica que ela vai dispor sobre:

[...] a política nacional de habitação e de planejamento territorial, coordenando a ação dos órgãos públicos e orientando a iniciativa privada no sentido de estimular a construção de habitações de interesse social e o financiamento da aquisição da casa própria, especialmente pelas classes da população de menor renda.

Infere-se, com base no trecho compartilhado, que o Serfhau foi instituído mais como um órgão voltado às políticas compensatórias habitacionais, a despeito do planejamento urbano com alto respaldo técnico e acadêmico que acabou promovendo. Mesmo que o órgão tenha representado avanço em termos de valorização da questão urbana pelo Estado, é necessário ponderar que a autarquia, em termos institucionais, estava ao lado de entidades como o Serviço Nacional de Assistência aos Municípios (Senam) e o Serviço de Proteção aos Índios (SPI) (MINTER, 1967), ou seja, vinculado a quesitos territoriais e não essencialmente urbanos.

Isso porque o Serfhau absorveu, enquanto entidade, as funções da antiga Fundação da Casa Popular (FCP), fundada na década de 1940. Em um ofício datado de 1975, ${ }^{11}$ lê-se que todos os imóveis construídos pela antiga FCP passariam a ser administrados pela Caixa Econômica Federal (CEF), tal como posteriormente ocorreria com os empreendimentos do BNH. Esse quadro mudou somente com a

11. Ofício Serfhau/GS/574/75 de 13 de maio de 1975. Acervo Minter/AN BSB. 
regulamentação do órgão, que aconteceu em 1966, composto pelo Escritório de Pesquisa Econômica Aplicada (Epea), cujo artigo $1^{\circ}$ indica que o Serfhau se constitui em uma

[...] entidade elaboradora e coordenadora da política nacional no campo de planejamento local integrado, estabelecida dentro das diretrizes da política de desenvolvimento regional em articulação com o Ministério do Planejamento e o Ministério de Coordenação dos Organismos Regionais. ${ }^{12}$

Publicações da época apresentam aspectos sobre a regionalização. O II Plano Nacional de Desenvolvimento (1974), por exemplo, versava sobre a Política Nacional de Desenvolvimento Urbano (PNDU) e é considerado o primeiro plano nacional a incorporar criticamente as clivagens regionais do país, ainda que conte com respaldo esparsos e medidas pontuais das administrações anteriores. Segundo Amêndola:

[...] a concepção de ordenamento territorial para o governo brasileiro compreendia promover a organização da rede urbana em um sistema que satisfizesse as aspirações dos habitantes das diferentes regiões do país, e traria como consequências a reorientação dos fluxos migratórios, através da orientação dos investimentos públicos e privados em sintonia com os objetivos do desenvolvimento regional; iniciaria um processo de descompressão urbana, reorientando investimentos para induzir o crescimento das cidades médias e núcleos interiorizados (2011, p. 178).

O documento propôs estratégias para as regiões como o Nordeste, a Amazônia e o Centro-Oeste, por vezes nominados de "ilhas de subdesenvolvimento" (MINTER, 1967, p. 4) em consonância com a circulação de conceitos em nível transnacional. No mesmo sentido, foi sugerida a dinamização do núcleo industrial da região Centro-Sul, evitando sua centralização na área metropolitana de São Paulo. ${ }^{13}$

A institucionalização da regionalização junto ao poder público incluiu, igualmente, o treinamento de técnicos. Processos decorrentes dos Minter e do Miniplan informam o envio de funcionários dos órgãos ligados à administração urbana ao exterior, para participação em congressos e cursos da área. Em 1971, por exemplo, aventou-se que funcionários da administração federal frequentassem cursos

12. Decreto n. 59.917, de 30 de dezembro de 1966.

13. Inúmeras medidas são lançadas, tais como: Programa de Polos Agrícolas e Agrominerais da Amazônia, Programa de Desenvolvimento de Áreas Integradas do Nordeste, Programa de Desenvolvimento da Região Geoeconômica de Brasília, Programas de Aproveitamento Integrado de Vales. 
de pós-graduação na Universidade Federal da Paraíba com vistas à preparação de especialistas para colocar em prática o Plano Nacional de Irrigação.

Nessa direção, na mesma medida em que se desejava a otimização das atividades de planejamento, a centralização institucional se fortalecia, conforme explícito em organogramas institucionais anexos aos ofícios do Minter, que sugerem uma configuração institucional baseada em elementos, como: i) cabeças de sistema; ii) órgãos executivos iii) meios; iv) implementação. A política de desenvolvimento urbano estava sendo burocratizada: caberia a um órgão fornecer recursos financeiros, a outro realizar a assistência técnica e ao Minter, coordenar e autorizar todas as atividades solicitadas.

Outro exemplo dessa constante setorização foi a criação de órgãos para o financiamento dos planos, caso do Fundo Nacional de Desenvolvimento Urbano (FNDU) ${ }^{14}$ e sua execução, como o Programa Estratégico de Desenvolvimento (PED), que avaliava o sistema nacional de planejamento local, assim como as primeiras experiências dos planos de desenvolvimento local integrado, e previa: i) análise da estrutura especial do Brasil; ii) modificações previsíveis dos fatores que afetam o desenvolvimento urbano; iii) análise das estruturas institucionais existentes (BRASIL, 1971, p. 11).

Fizeram parte dessa concepção de organização, que foi a segunda tentativa do Minter de atender de forma satisfatória o desordenado crescimento urbano, após a CNPU, órgãos como o Sistema de Desenvolvimento Local (SDL), o Centro de Informações para o Desenvolvimento Urbano Local (Cidul) e o Instituto Nacional de Desenvolvimento Urbano e Local (Indul). Tais entidades pioneiras foram as responsáveis pela elaboração e a implantação dos Planos de Desenvolvimento de Regiões Metropolitanas.

Um dos passos dentro do projeto da ditadura civil-militar de desenvolvimento regional foi a criação de órgãos para a coleta de dados e índices sobre a sociedade, o território e a economia do Brasil. Entidade de destaque, nesse âmbito, foi o Ipea, criado em 1964 com a nomenclatura de Epea. ${ }^{15}$

O Ipea se coadunou com atividades de pesquisa desempenhadas pelo IBGE no que diz respeito à sistematização de dados e chegou a encampar as funções desse órgão por alguns anos. Suas atribuições estavam muito além da produção de conhecimento técnico, uma vez que, entre suas incumbências, se destacavam: I -

\footnotetext{
14. Lei n. 6.256/75.

15. O Epea, com a Reforma Administrativa de 1967, passou a chamar-se Instituto de Pesquisa Econômico-Social Aplicada e, posteriormente, Instituto de Planejamento Econômico e Social, em 1969. Em maio de 1990, tornou-se definitivamente Instituto de Pesquisa Econômica Aplicada.
} 
auxiliar a Secretaria de Planejamento da Presidência da República na elaboração dos programas globais de governo e na coordenação do sistema nacional de planejamento; II - auxiliar a Secretaria de Planejamento da Presidência da República na articulação entre a programação e os orçamentos anuais e plurianuais do Governo Federal; III - promover atividades de pesquisa aplicada nas área econômica e social; IV - promover atividades de treinamento para o planejamento e pesquisa aplicada. Em 1976, o Instituto de Pesquisa (Inpes), de caráter acadêmico, ganhou sede no Rio de Janeiro.

Na capital federal foi lançado o Instituto de Planejamento (Iplan), cujas atribuições são de caráter técnico. Todavia, o Ipea foi concebido com o diferencial de divulgar dados para auxiliar o governo federal na formulação de políticas públicas e programas de desenvolvimento. Inúmeras publicações foram realizadas depois desse desígnio, desde os Planos Decenais até Planos de Desenvolvimento Econômico, Diretrizes para Regiões Metropolitanas, entre outros, tais como os projetos de colonização. ${ }^{16}$

Foram também instituídos o Sistema de Planejamento Local Integrado, em 1965, e o Fundo de Financiamento de Estudos de Projetos e Programas (Finep). O BNH passou a operar segundo essa lógica e, em 1972, foram lançados três fundos de desenvolvimento urbano, cada um deles voltado às ditas regiões menos desenvolvidas do país: Nordeste, Leste, Centro-Oeste e Sul, Amazônica.

Fator notório na relação entre desenvolvimentismo e regionalização do território foi a permanência do incentivo às rodovias no país. Já em 1964, lançou-se o Plano Nacional de Viação, com um capítulo dedicado ao Plano Rodoviário Nacional, fixando nomenclaturas e diretrizes das rodovias que deviam interligar as capitais ao interior, as zonas de turismo, à fronteira etc. (UEDA, 2007, p. 177-78). Destaca-se que os traçados foram escolhidos em função dos serviços que deviam prestar, revelando o forte ideal de funcionalismo presente na organização territorial. Somou-se à integração do território que se esboçava no período anterior a construção das bases de uma verdadeira fluidez do território, processo corroborado pelos avanços da informatização. O projeto atingiu, até mesmo, o território marítimo do Brasil, que, em 1970, foi ampliado de 12 para 200 milhas, contra a vontade dos Estados Unidos.

O jornal O Estado de S. Paulo, em sua edição do dia 21 de fevereiro de 1973, saudava o então presidente do país, Emílio Garrastazu Médici (1969-74), ao divulgar

16. Consultar, por exemplo: CORRÊA, R. L; DAVIDOVICH, F. R. Centros de polarização do Brasil (metodologia adotada). In: Esboço preliminar de divisão do Brasil em espaços homogêneos e espaços polarizados. Rio de Janeiro: IBGE, Conselho Nacional de Geografia, Divisão de Geografia, 1967, pp.1-7. 
o Plano Modular Integrado nacional, cujo "objetivo era ocupar vazios demográficos”. ${ }^{17}$ Um dos expoentes da perspectiva de interiorização e controle territorial foi o Projeto Rondon, em 1967. Recentemente reativado (2005), ele envolvia estudantes universitários na participação de atividades de caráter assistencial em áreas do país de difícil acesso, principalmente nas regiões Norte e Nordeste.

A essas áreas foram dirigidos os principais projetos que envolveram a construção de rodovias, o incentivo à habitação e à instalação de indústrias, entre outras medidas que legitimavam o mote "ocupar para não entregar”, associado aos governos militares. A proposta tinha respaldo histórico: a "Marcha para o Oeste”, promovida pelo Governo Vargas, foi uma conhecida tentativa de interiorização do país com vistas à manutenção da soberania nacional. Também a Constituição, elaborada sob a vigência do governo de Gaspar Dutra (1946-51), datada de 1946, já havia incluído artigos referentes à colonização de áreas, à defesa contra as secas, à valorização da Amazônia e à organização dos campos de viação, entre outras medidas.

Envolto em críticas e de difícil operacionalização por parte do Estado, o projeto de influência francesa promovido pelo IBGE e pelo Ipea cedeu lugar, aos poucos, para a matriz anglo-americana, já bastante influente junto à área do planejamento urbano (ALMEIDA, 2000, p. 176). Tal período marca uma mudança de paradigma dentro do IBGE, da geografia humana em direção à geografia quantitativa, ${ }^{18}$ embora esta última nunca tenha sido totalmente preponderante, como está explicitado nas próprias publicações da Revista Brasileira de Geografia (LAMEGO, 2000, p. 8).

Nos termos colocados, o panorama acima fornece suporte para uma compreensão do "complexo amálgama de influências causais” (SCHMIDT, 1983, p. 13) que definiu o planejamento urbano a partir do viés da regionalização no Brasil. Essa conjuntura, por sua vez, espelha as origens de algumas características da urbanização e da metropolização brasileira, tais como a intensidade de fluxos de pessoas, de mercadorias e de capitais, a concentração de atividades de gestão e administração, a utilização de tecnologias de informação e comunicação, a exacerbação da associação entre o capital financeiro e o da indústria da construção e, enfim, a produção de um modo de viver e de consumir especificamente ligado às metrópoles (LENCIONI, 2013).

17. Recorte de jornal anexo à carta datada de 22 de fevereiro de 1973, sob protocolo n. 382. Procedência Vergueiro Planejamento Serviços Ltda. Acervo Minter/AN BSB.

18. Aqui, observa-se uma mudança de influência da matriz francesa, dominada por Rochefort e Perroux, para a de matriz anglo-americana, cujos nomes mais influentes foram John P. Cole, Brian Berry e John Friedman. Seus principais interlocutores no IBGE serão Pedro Geiger e Roberto Lobato Corrêa. 


\title{
3. Limites e significados da regionalização no projeto desenvolvimentista ditatorial
}

Ainda que muitas propostas arroladas não tenham se constituído em novidades instituídas pelo governo das Forças Armadas, foi sob sua égide que foram implementados órgãos, autarquias e ministérios servidos por amplos recursos para a condução da questão urbana. A atenção dispensada à regionalização foi, afinal, adotada para fins de interligação, ocupação e domínio técnico-territorial.

Apesar dos projetos de interiorização e dos diagnósticos de vazios demográficos, o Brasil apresentava relativa dispersão de centros urbanos quando comparado a países como a Argentina, onde 35\% da população vivia em Buenos Aires, e a Venezuela, onde $21 \%$ dos residentes moravam na capital, Caracas (BRASIL, 1965, p. 4). Arthur Bernady Santana assevera o caráter excludente das tentativas de colonização por meio do desenvolvimento regional, pois:

\begin{abstract}
[...] esse "vazio", ao qual os textos e discursos dos governos militares se referem, nega a existência de mais de 170 nações biblioindígenas, desconhecendo que esse território era terra de ocupação antiga, que abrigava posseiros, garimpeiros, populações quilombolas, entre outros indivíduos. A política dos governos militares para a Amazônia utilizou o lema "ocupar para não entregar", como se aquela imensa região fosse um “vazio demográfico” (SANTANA, 2009, p. 3).
\end{abstract}

Ironicamente, as tentativas de equiparação e integração nacional condicionadas pelas potencialidades industriais que cada região apresentava causaram o efeito reverso, considerando que as políticas de desenvolvimento industrial se desvinculavam de preocupações com os condicionamentos espaciais, a não ser quanto às possíveis vantagens locacionais e econômicas, provocando "o agravamento das desigualdades inter e intrarregionais e, nos focos de maior concentração das atividades, a elevação dos níveis de poluição (BERNARDES, 1986, p. 86).

Não só a quantidade de instituições designadas no período, mas, igualmente, as tecnologias e os recursos financeiros aplicados, consagraram esse quadro temporal como peculiar, tratando-se da emergência da regionalização com uma pauta de Estado associada à valorização de uma tecnocracia cujas ressonâncias se fizeram presentes, por exemplo, na ascensão da geografia quantitativa no Brasil (LAMEGO, 2014). O que não anulou o fato de os críticos dos projetos de desenvolvimento regional terem se encontrado, muitas vezes, desafiados por efeitos contrários àqueles que objetivavam, como a nucleação urbana.

A década de 60 caracterizou-se por uma tentativa de ampliação das políticas de descentralização industrial que visavam diminuir as de- 
sigualdades entre as regiões brasileiras, priorizando o Nordeste via adoção de incentivos fiscais para implantação de parques industriais nas suas duas maiores metrópoles, Recife e Salvador. Tais políticas gerenciadas pela Superintendência do Desenvolvimento do Nordeste (Sudene) não deram, ao longo daqueles anos, resultados que pudessem ser sentidos claramente por suas economias (ALMEIDA, 2000, p. 181).

O planejamento territorial, nesses termos, se configurou como um campo profissional tanto quanto uma função de governo. Autores como Lamparelli, Camargo e George explicam que o Estado se tornou um normatizador das contradições do espaço interurbano, atuando como o próprio "produtor do espaço urbano" (2007, p. 13).

As práticas de regionalização estiveram circunscritas para muito além das fronteiras do campo do planejamento urbano. Nesse período específico, sua estrutura esteve associada à criação do que parcela da historiografia dedicada à ditadura civil-militar chamou de Estado de Segurança Nacional (ALVES, 1989) e fez parte da organização de um território de ordem, diante da situação avaliada como calamitosa. Conforme Serra:

[...] o advento do centralismo autoritário ocorreu em meio à crise do processo de urbanização acelerada e frequentemente é associado a ele. De fato, é entre os anos de 1950 e 1970 que ocorrem as taxas mais elevadas de crescimento da população urbana no Brasil. Ao final dos anos 50 , às vésperas do golpe de 64 , o processo encontra-se em sua fase mais aguda, fazendo-se sentir na rede urbana brasileira todas as suas características mais críticas (1991, p. 146)

O ideal de controle esteve representado, de maneira clara, na ideologia da segurança nacional. A sociedade brasileira deveria funcionar como um sistema integrado, com as partes ajustadas ao ritmo do todo. O Estado militar teria o papel de regulador autoritário, capaz de eliminar e diluir os conflitos que porventura viessem a ameaçar sua integridade (REIS, 2014, p. 116). Com base nessas prerrogativas, o entendimento era de que as regiões deviam ser caracterizadas de acordo com elementos em comum ao território ao qual pertenciam e, sobretudo, responder ao projeto nacional de integração e industrialização, um dos motes notáveis do nacional-estatismo. Conforme Bomfim (2015, p. 367):

[...] o próprio nacional desenvolvimentismo e todos seus elaboradores, no Brasil, na França e em outros países, acreditavam na "correção", a cargo do Estado, das desigualdades regionais, realizada por meio da penetração da industrialização e dos polos "modernos" 
da economia, de maneira a paulatinamente superar e vencer o "atraso", postura que pareceria estar acima de qualquer ambiente político-institucional.

Nesse sentido, a regionalização do território emerge como uma das categorias no qual o autoritarismo e o desenvolvimentismo vão se locupletar: colonização, desbravamento de matas, construção de estradas e diminuição de distâncias foram os principais tópicos da agenda nacional de planejamento no período em tela. Entre as principais decorrências, figuram definições precisas de zonas de acordo com critérios econômicos; a massiva coleta de dados, enquanto meio de conhecimento e, portanto, controle; e inúmeras desapropriações, usualmente para fins industriais e não sociais. Em outras palavras, a questão urbana e o desenvolvimento regional passaram a ser pautas de desenvolvimento econômico nacional. Todavia, deve-se considerar que o almejado equilíbrio territorial era preconizado mais em termos conceituais do que efetivamente, visto que as cidades:

[...] correspondiam ao grande meio rentável do capital investido pelo Estado e pela iniciativa privada. Não era interesse dos governantes, desta forma, limitar a concentração de investimentos nestes locais ou promover a descentralização dos grandes centros urbanos, afinal, a própria geração de empregos urbanos era uma maneira de conter os conflitos sociais (MONTE-MÓR apud VERRI, 2014, p. 104).

É importante registrar, nesses termos, que o desenvolvimentismo foi fruto de um pacto tácito entre os grandes interesses rurais e o capitalismo industrial, que teve como principal consequência a reprodução ampliada e, a partir de então, modernizada da oligarquia rural brasileira (MOREIRA, 2008, p. 190) à custa do desenvolvimento social. Tais oligarquias souberam converter o projeto desenvolvimentista a seu favor, pois:

[...] o aprofundamento industrial exigia, simultaneamente, a ampliação do mercado interno consumidor de industrializados, bem como uma maior articulação física e econômica entre "litoral" e "interior", isto é, entre os setores agropecuário e industrial (MOREIRA, 2008, p. 184).

Por esse motivo, um dos principais críticos da indução de polos foi Bernard Kayser, geógrafo francês para quem a estrutura dualista do Brasil - com zonas voltadas à exportação e outras totalmente à subsistência - não comportaria uma integração. Vale lembrar, em tempo, que a proposta de regionalização esbarrou em questões como os limites administrativos e jurídicos que delimitavam as cidades e 
os estados brasileiros. As dificuldades quanto ao projeto de desenvolvimento regional foram arroladas no Plano Decenal, em 1967:

conhecimento desigual do território nacional; impossibilidade de tornar equivalente a hierarquia de partes do país, distanciadas no espaço e no tempo; falta de conhecimento da dinâmica regional e do fenômeno dominante capaz de identificar o tipo de região (MINISTÉRIO DE PLANEJAMENTO E COORDENAÇÃO GERAL, 1967b, p. 113).

O planejamento, no contexto autoritário, tratou-se de "uma imposição de formas que se constituem em uma imposição de técnicas na medida em que as formas respondem à finalidade e às estruturas” (MORAES, 2013, p. 40). O projeto desenvolvimentista, associado ao autoritarismo, encontrou nos projetos de regionalização o seu território de materialização por excelência. Esse traço pode ser observado na caracterização de regiões unicamente a partir de critérios econômicos, nos privilégios legislativos concedidos à instalação de fábricas fora das grandes capitais, em planos e projetos de remoção de bairros residenciais em prol de indústrias e, finalmente, na associação da ideia do conceito de regionalização ao de desenvolvimento.

\section{Considerações finais}

O projeto nacional de regionalização entendia a industrialização como a principal alternativa ao subdesenvolvimento atribuído ao Brasil junto à ordem internacional. Desta maneira, é imprescindível ressaltar que as propostas de regionalização do território brasileiro integraram os poderes público e privado no projeto nacional-desenvolvimentista de industrialização. Segundo Campos (2012, p. 111):

[...] através da implantação de uma infraestrutura regional e realização de obras, havendo em geral preferência para empreiteiras locais, o que correspondia aos interesses organizados e alojados nessas instituições e às próprias diretrizes das políticas que norteavam a ação desses organismos, dado que elas intentavam fortalecer as empresas da região.

Esse modelo não foi iniciado com a ditadura, tampouco totalmente abandonado ao seu fim, mas assumiu uma configuração particular durante as décadas de 1960 e 1970, induzindo desigualdades territoriais em todas as escalas, fenômeno que seria uma das marcas das metrópoles no final do século XX (VELTZ, 1999). 
A consideração do conjunto de estudos detalhados é crucial para a percepção das abordagens conferidas ao fenômeno urbano no Brasil que não se contrapõem, mas também não são consensuais, em face dos conflitos de natureza política, científica e corporativa que incluíram a institucionalização da problemática urbana no Brasil. Além de serem desenhados com base em perspectivas teóricas diversas, tais enfoques desvelam disputas em torno da legitimidade da interpretação do fenômeno urbano brasileiro, manifestadas na criação de uma série de organismos profissionais embasados em diferentes áreas do conhecimento, como a Geografia, o Urbanismo e a Economia.

O reconhecimento de projetos de regionalização como um campo para a condução dos problemas urbanos por parte da opinião pública e pelo Estado ocorreu em meio à sua centralização e ao silenciamento de pontos que privilegiavam a esfera social. Isso porque as mudanças nos âmbitos técnicos e administrativos não foram acompanhadas de reformas sociais e agrárias, dado substancial quando se tem em conta que, historicamente, a propriedade sobre a terra no Brasil não está necessariamente associada à produção sobre ela.

Assim, a ênfase no reerguimento da economia por intermédio do crescimento industrial anulou qualquer veleidade de serem considerados os problemas espaciais em sua complexidade (BERNARDES, 1986, p. 80). Não obstante, pesquisas recentes evidenciam que projetos desenvolvimentistas regionalizados, como aqueles que ocorreram na Amazônia, se revelaram uma catástrofe diante da emergência do ambientalismo (ACKER, 2014). Nesse sentido, a indução econômica dos territórios pode ser notada, de forma integral, na divisão geopolítica mundial, na internacionalização de empresas e na tentativa de regionalização, cuja principal consequência na atualidade é a nucleação urbana. ${ }^{19}$

\section{Referências bibliográficas}

ACKER, A. Volkswagen in the Amazon. The tragedy of global development in modern Brazil. Cambridge: Cambridge University Press, 2017.

ALMEIDA, R. S. de. A geografia e os geógrafos do IBGE no período de 1938-1998. Tese de Doutorado. Rio de Janeiro: Universidade Federal do Rio de Janeiro, Programa de Pós-Graduação em Geografia do Instituto de Geociências, 2000.

ALVES, M. H. M. Estado e oposição no Brasil (1964-1984). 5. ed. Petrópolis, RJ: Vozes, 1989.

19. O presente artigo é fruto de um projeto de pesquisa que tem sido realizado com o apoio do CNPq (Chamada MCTIC/CNPq n. 28/2018). É intitulado "Planejando o Terceiro Mundo": transnacionalidade e circulação de ideias em experiências de planejamento urbano no Sul do Brasil. 
AMENDOLA, M. Uma avaliação do ordenamento territorial no processo de planejamento governamental: estudo do Rio de Janeiro. Tese de Doutorado. São Paulo: Universidade de São Paulo, Departamento de Geografia, 2012.

BERNARDES, L. Política urbana: uma análise da experiência brasileira. Anál. e Conj., Belo Horizonte, 1 (1): 83.119, jan./abr. 1986.

BIELSCHOWSKY, R. Pensamento econômico brasileiro: o ciclo ideológico do desenvolvimentismo. Rio de Janeiro, Ipea/Inpes, 1988.

BOMFIM, P. R. de A. Michel Rochefort e o Instituto Brasileiro de Geografia e Estatística na década de 196o. Soc. \& Nat., Uberlândia, v. 27, n. 3, pp. 365-78, 2015.

BRANDÃO, C. Território e desenvolvimento: as múltiplas escalas entre o local e o global. Campinas: Ed. da Unicamp, 2012.

BRASIL. Pesquisa sobre polos de desenvolvimento e regiões homogêneas no Brasil. Miniplan Epea. s/d. Acervo Biblioteca Ipea/Rio de Janeiro.

. Programa de acompanhamento dos Planos Nacionais de Desenvolvimento. Normais Gerais. Miniplan: Secretaria de Planejamento, 1974.

Programa Estratégico de Desenvolvimento: tabelas de recursos e aplicações por programa. 1968-1970. Brasília: Miniplan 1971, p. 11.

. Ministério Extraordinário para o Planejamento e Coordenação Econômica. Programa de ação econômica do governo revolucionário (1964-1966). Brasília: 1967.

. BNH/Epea Desenvolvimento urbano no Brasil. Bases para a formulação de uma política nacional de desenvolvimento urbano e para a implantação de um Sistema Nacional para o Planejamento do Desenvolvimento Local Integrado. Brasília: BNH/Epea, 1965, p. 4.

CAMARGO, A. R.; LAMPARELLI, C. M.; GEORGE, P. S. C. Nota introdutória sobre a construção de um objeto de estudo: o urbano. Etc: Espaço, Tempo e Crítica. n. 1, vol. 1., 2007.

CAMPOS, P. H. P. A ditadura dos empreiteiros: as empresas nacionais de construção pesada, suas formas associativas e o Estado ditatorial brasileiro (1964-1985). Tese de Doutorado. Programa de Pós-Graduação em História da Universidade Federal Fluminense. Rio de Janeiro: UFF, 2011.

CERVO, A. L.; BUENO, C. Inserção internacional: a construção dos conceitos brasileiros. São Paulo: Saraiva, 2008.

DÉAK, C. “O processo de urbanização no Brasil: falas e façanhas”. In: DÉAK, C.; SCHIFFER, S. R. (Orgs.). O processo de urbanização no Brasil. São Paulo, Edusp, 1999.

FARIA, R. S. de. O Departamento Nacional de Urbanismo e a institucionalização do setor de urbanismo no Governo Federal brasileiro: um contínuo processo histórico. Oculum ensaios: Revista de Arquitetura e Urbanismo. Campinas, vol. 12, n. 2, pp. 311-33, 2015.

FELDMAN, S. Planejamento e zoneamento: São Paulo, 1947-1972. São Paulo: Edusp/Fapesp, 2005.

1950: a década de crença no Planejamento Regional no Brasil. In: XIII Anais do Encontro Nacional da Anpur. Florianópolis: Anpur/UFSC, pp. 1-23, 2009. 
FERNANDES, A. “Urbanismo como política (1930-1945): formulações e experiências”. In: REZENDE, V. (Org.). Urbanismo na Era Vargas: a transformação das cidades brasileiras. Niterói: UFF/Intertexto, 2012.

FERRARI, C. Dicionário de urbanismo. São Paulo: Disal, 2004.

FERREIRA, M. Planejamento urbano nos tempos do Serfhau: o processo de construção e implementação do Plano Diretor de Desenvolvimento Integrado de Franca. Tese deDoutorado em Arquitetura e Urbanismo. São Carlos: USP, 2007.

LAMEGO, M. O IBGE e a geografia quantitativa brasileira. Terra Brasilis (Nova Série) [online], 3, 2014. Disponível em: http:// journals.openedition.org/terrabrasilis/1015. Acesso em 24 out. 2019.

LEME, M. C. da S. "A formação do pensamento urbanístico no Brasil 1965-1985”. In: LEME, M. C. da S.; SOUZA, C. F. de; ALLII, E. (Orgs.). Urbanismo no Brasil, 1895-1965. São Paulo: Studio Nobel, 1999.

LENCIONI, S. Metropolização do espaço: processos e dinâmicas. In: FERREIRA, A. et al. Metropolização do espaço: gestão territorial e relações urbano-rurais. Rio de Janeiro: Consequência, 2013. pp. 17-34.

MARICATO, E. As ideias fora do lugar e o lugar fora das ideias. Planejamento urbano no Brasil. In: ARANTES, O. B. F.; VAINER, C.; MARICATO, E. (Orgs.) A cidade do pensamento único: desmanchando consensos. Petrópolis: Vozes, 2000, pp. 121-192.

MINTER. Jurisdição e competência. Rio de Janeiro: Rio Gráfica e Editora, 1967, p. 4.

MINISTÉRIO DO PLANEJAMENTO E COORDENAÇÃO GERAL. Diretrizes de Governo. Programa estratégico de desenvolvimento. Brasília: Acervo Ibero-Amerikanisches Institut Berlin, 1967a, p. 143.

Plano Decenal de Desenvolvimento Econômico e Social. Tomo VII. Vols. 1 a 6 (Desenvolvimento Regional e Urbano). Documento preliminar. Rio de Janeiro: Ipea, Acervo Ipea/RJ, $1967 \mathrm{~b}$.

MORAES, A. C. R. Território na geografia de Milton Santos. São Paulo: Annablume, 2013.

MOREIRA, V. M. L. Os anos JK: industrialização e modelo oligárquico de desenvolvimento rural. In: FERREIA, J.; DELGADO, L. de A. N. (orgs.) Brasil Republicano: o tempo da experiência democrática. Rio de Janeiro: Civilização Brasileira, 2008.

REIS, D. A. A ditadura faz cinquenta anos: história e cultura política nacional-estadista. In: REIS, D. A.; RIDENTI, M.; MOTTA, R. P. S. (Orgs.). A ditadura que mudou o Brasil: 50 anos do golpe de 1964. Rio de Janeiro, Zahar, 2014.

ROCHEFORT, M. O problema da regionalização do Brasil. Rio de Janeiro: Miniplan/Ipea, 1967.

SANTANA, A. B. A BR-163: "ocupar para não entregar”: a política da ditadura militar para a ocupação do "Vazio" Amazônico. In: Anais do XXV Simpósio Nacional de História/ Anpuh. Fortaleza, 2009.

SANTOS, M. A urbanização brasileira. São Paulo: Edusp, 2013.

SERRA, G. Urbanização e centralismo autoritário. São Paulo: Edusp, 1991. 
SCHMIDT, B. O Estado e a política urbana no Brasil. Porto Alegre: Ed. da UFRGS/L\&PM, 1983.

SINGER; P. Economia política da urbanização. São Paulo: Brasiliense, 1987.

SOUZA, C. F. de; ALMEIDA, M. S. de. Modernidade e autoritarismo: urbanismo em tempos ditatoriais. Porto Alegre, 1937-1945. In: REZENDE, V. (Org.). Urbanismo na Era Vargas: a transformação das cidades brasileiras. Niterói: Editora da UFF, 2012, p. 197-232.

STEINBERGER, M. Planejamento local integrado: uma fase necessária ao desenvolvimento urbano planejado. Dissertação de Mestrado de Engenharia da Produção. Rio de Janeiro: Universidade Federal do Rio de Janeiro, 1976.

UEDA, V. “O papel das redes técnicas: transportes, energia e telecomunicações”. In: GERTZ, R. (Dir.); GOLIN, T.; BOEIRA, N. (Coord.). História geral do Rio Grande do Sul: República: da revolução de 1930 à ditadura militar (1930-1985). Passo Fundo: Méritos, 2007.

VERRI, F. O planejamento urbano integrado e a atuação do Serfhau no Rio Grande do Sul (19641975). Dissertação de Mestrado. Programa de Pós-Graduação em Planejamento Urbano. Porto Alegre: Universidade Federal do Rio Grande do Sul, 2014.

VELTZ, P. Mundialización, ciudades y territorios. La economía de archipelago. Barcelona: Ariel, 1999.

VILLAÇA, F. Espaço intraurbano no Brasil. São Paulo: Studio Nobel, 1998. 


\section{Danielle Heberle Viegas}

Arquiteta-urbanista, mestre e doutora em Filosofia. Doutora em História (PUCRS/Freie Universität Berlin), professora do Programa de Pós-Graduação em Memória Social e Bens Culturais (Universidade Lasalle/Unilasalle), professora dos cursos de História e Arquitetura e Urbanismo (Unilasalle) e pesquisadora do Observatório das Metrópoles (Núcleo Porto Alegre). Colaboradora da rede UEDXX (Urbanism of European Dictatorship during the $\left.X X^{\text {th }}\right)$.

Email: danielle.viegas@unilasalle.edu.br

ORCID: 0000-0003-4299-822X

Submissão: 13 de fevereiro de 2019.

Aprovação: 16 de novembro de 2019.

Como citar: VIEGAS, D. H. Território, ditadura e desenvolvimento: perspectivas históricas sobre os programas de regionalização no Brasil. Revista brasileira de estudos urbanos e regionais. v.22, E202009pt, 2020. DOI 10.22296/2317-1529.rbeur.202009pt

Artigo licenciado sob Licença Creative Commons CC BY-NC 4.o. https://creativecommons.org/licenses/by-nc/4.o/deed.pt_BR 